\title{
Effect of screening on incidence of and mortality from cancer of cervix in England: evaluation based on routinely collected statistics
}

\author{
Mike Quinn, Penny Babb, Jennifer Jones, Elizabeth Allen on behalf of the United Kingdom
}

Association of Cancer Registries

\begin{abstract}
Objective To assess the impact of screening on the incidence of and mortality from cervical cancer. Design Comparison of age specific incidence and mortality before and after the introduction of the national call and recall system in 1988.

Setting England.

Subjects Women aged over 19 years.

Results From the mid-1960s, the number of smears taken rose continuously to 4.5 million at the end of the 1980s. Between 1988 and 1994, coverage of the target group doubled to around $85 \%$. Registrations of in situ disease increased broadly in parallel with the numbers of smears taken. The overall incidence of invasive disease remained stable up to the end of the 1980s, although there were strong cohort effects; from 1990 incidence fell continuously and in 1995 was $35 \%$ lower than in the 1980s. The fall in overall mortality since 1950 accelerated at the end of the 1980s; there were strong cohort effects. Mortality in women under 55 was much lower in the 1990s than would have been expected.

Conclusions The national call and recall system and incentive payments to general practitioners increased coverage to around $85 \%$. This resulted in falls in incidence of invasive disease in all regions of England and in all age groups from 30 to 74 . The falls in mortality in older women were largely unrelated to screening, but without screening there might have been 800 more deaths from cervical cancer in women under 55 in 1997.
\end{abstract}

\section{Introduction}

Invasive cervical cancer is the second most common cancer in women worldwide, but $80 \%$ of cases occur in developing countries. The incidence of the disease has been falling in many western countries, but not in Great Britain, over the past 40 years. The cervical smear test was developed over 50 years ago, and screening began in Great Britain, some Nordic countries, and parts of North America in the 1960s.

In the late 1980s the incidence of cervical cancer in Great Britain was in the middle of the European range. But mortality was among the highest of the developed countries, and in Europe only Denmark had a higher rate. Survival improved slightly in England during the $1980 \mathrm{~s},{ }^{1}$ but remained worse than in most other European countries. ${ }^{2}$ It is much poorer for later than earlier stage disease. ${ }^{3}$

A link between cervical cancer and a sexually transmitted infection was first suggested because it was associated with women who had had many sexual partners, or whose partner had, and an early age at first intercourse. ${ }^{4}$ Evidence for the aetiological role of human papillomavirus has accumulated from both molecular and epidemiological studies. ${ }^{5}$ Other risk factors include smoking, oral contraceptives, parity, cervical trauma during childbirth, and hormonal influences of pregnancy. ${ }^{6}$ Changes in these risk factors over time will have affected the incidence of cervical cancer.

Although cervical screening in England started in 1964, for over 20 years it failed to achieve sufficient coverage of women or follow up of all women with positive results. ${ }^{7}$ During the 1980 s, several recommendations were made to improve the screening programme, and in 1987 an intercollegiate working party recommended that screens be repeated every three years for women aged 20 to 64 years. ${ }^{8}$ A national call and recall system was established in $1988 .{ }^{9}$ In 1996 , $60 \%$ of district health authorities operated a 3 year recall. ${ }^{10}$ Financial incentives were first introduced with general practitioner contracts in $1990{ }^{11}$

To assess the impact of the screening programme in England we examined trends in the numbers of smears taken and other characteristics of the screening programme; age specific trends for both in situ and invasive cervical cancer from 1971 to 1995; and age specific mortality from cervical cancer from 1950 to 1997.

\section{Subjects and methods}

The target age group for screening is 20 to 64 years; coverage is defined from 1995 onwards as the percentage of women aged 25 to 64 who had had a smear test in the previous 5 years (for 1988 to 1994, the previous $5^{1 / 2}$ years). ${ }^{12}$ The cancer registration system has been described elsewhere. ${ }^{13}$ Both the ascertainment and quality of data from cancer registries in Great Britain are generally high. ${ }^{14}$

Data on registrations of in situ and invasive cervical cancer from 1971 to 1991 are based on records of individual cases submitted to and validated by the Office for National Statistics. ${ }^{13}$ Figures for 1992 to 1995 are based on annual data supplied by the regional cancer registries (from cases that had been validated by the registries and aggregated into 5 year age groups). Only small overall differences exist between the two types of data. ${ }^{15}$ For the two regions for which data were not available for 1993 to 1995 , we assumed that the age specific incidence changed by the same amount as the average change in those regions for which data were available. Information on the stage of invasive disease was not available centrally.

We used published data on mortality from cervical cancer for 1950 to 1997. Although there have been three changes in the international classification of diseases over this period, no substantial alterations have occurred relating to cervical cancer. We adjusted the
Editorial

by Delamothe et al

National Cancer

Registration

Bureau, Office for

National Statistics,

Demography and

Health Division,

London

SW1V 2QQ

Mike Quinn,

director

Penny Babb,

senior cancer

epidemiologist

Jennifer Jones,

cancer epidemiologist

Elizabeth Allen,

cancer epidemiologist

Members of the

United Kingdom

Association of

Cancer Registries

are listed at the end

of the paper

Correspondence to:

Dr Quinn

mike.quinn@

ons.gov.uk 
mortality data to allow for procedural changes in the coding of cause of death. ${ }^{15}$

The registrations of in situ cervical cancer are not true incidence because, firstly, the disease is asymptomatic and cases are detected only by screening. Thus any changes over time in the number of women screened in different age groups will affect the numbers of registrations. Secondly, as women are not all screened annually, registrations are a mix of cases diagnosed in women screened for the first time and cumulative incidence since the previous screen for women who have been screened before.

The annual age specific rates for both incidence and mortality were calculated as the numbers of cases divided by the estimated mid-year population. Summary rates for incidence and mortality were directly age standardised by using the European standard population ( 5 year age bands). Confidence intervals for age specific and age standardised rates were calculated on the assumption that the number of cases followed a Poisson distribution ${ }^{16}$; the figures show typical $95 \%$ confidence intervals.

\section{Results}

Screening programme

The number of smears taken rose by about $6 \%$ each year until the early 1980 s, after which the increase was about $8 \%$ each year to the end of the decade; since then, about 4.5 million smears have been taken each year (fig 1). ${ }^{12}{ }^{17-19}$ The coverage of the target age group in the screening programme rose from $42 \%$ in 1988 to $85 \%$ in 1994, a level subsequently maintained (see fig 3). ${ }^{12}$ Coverage increased in all age groups, but particularly for older women (55 to 64 years).

\section{Carcinoma in situ}

The registration rate of carcinoma in situ rose broadly in line with the increasing numbers of smears taken, from about 10/100 000 women (2100 cases) in 1971 to 80 per100 000 (20 000 cases) in the mid-1990s (fig 1). The apparent large increase in the rates in 1984 and 1985 is due to the inclusion for the first time of registrations of cervical intraepithelial neoplasia grade III. Since 1987 the trends in registrations in women aged 20-24 and 25-29 have been continually upward, whereas women aged from 30 to 49 have shown no overall increase (fig 2). Registrations for older groups were consistently low and fell with age.

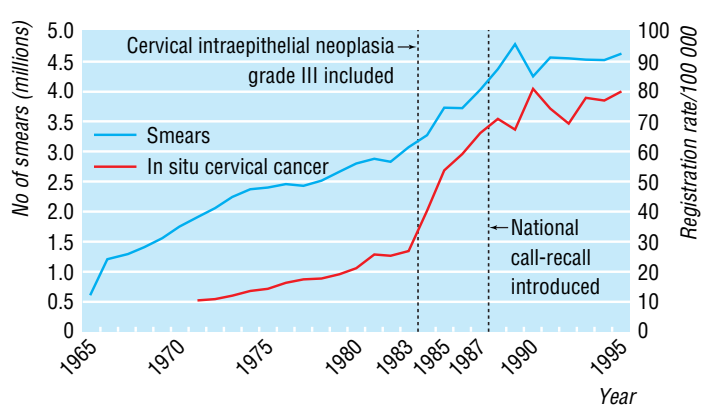

Fig 1 Number of cervical smears and directly age standardised rate of in situ cervical cancer, England, 1965-95

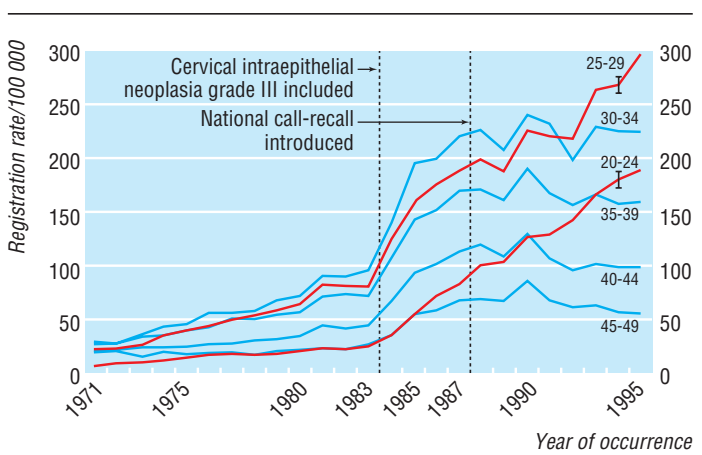

Fig 2 Age specific registrations of in situ cervical cancer in women aged 20-49, England, 1971-95

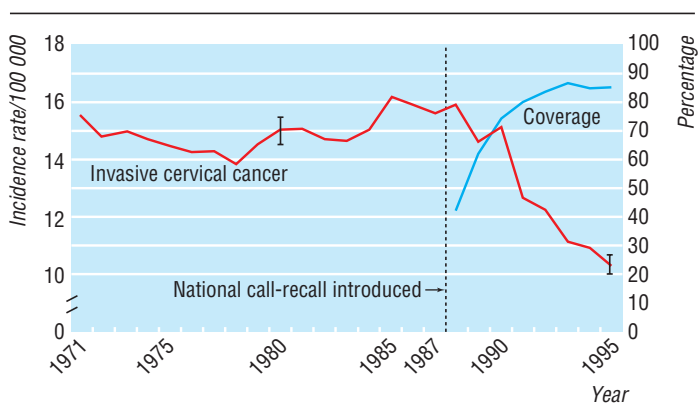

Fig 3 Age standardised incidence of invasive cervical cancer and coverage of screening, England, 1971-95

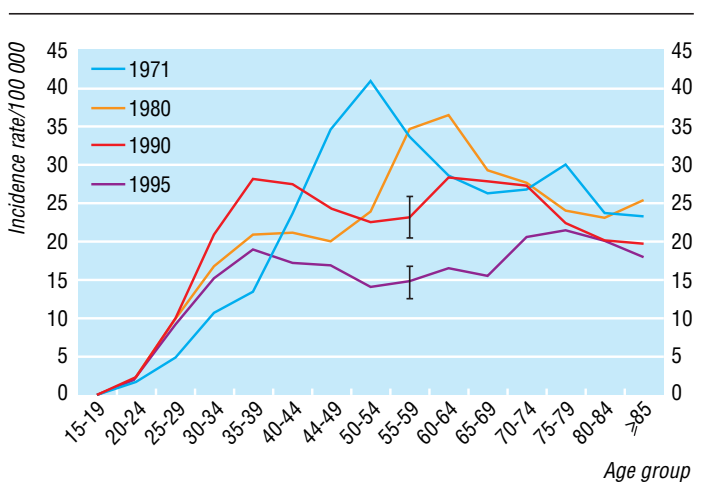

Fig 4 Age specific incidence of invasive cervical cancer in England for 1971, 1980, 1990 and 1995

\section{Invasive cancer}

From 1971 to the mid-1980s incidence remained between 14 and 16/100 000 (on average 3900 cases a year) (fig 3). It fell for five consecutive years after 1990, reaching just over 10/100 000 in 1995, about 35\% lower than in the mid-1980s. The 2900 cases diagnosed in 1995 represented 3\% of all malignancies (excluding non-melanoma skin cancer) in women. Age specific incidence has, however, changed differently in the various age groups (fig 4). In 1995, the overall pattern was similar to that in 1990 , but the incidence in every age group from 30-34 to 70-74 was substantially (and significantly) lower-by an average 9/100 000 (110 cases)

Incidence varied considerably across the regional health authorities: the crude rates in 1990 ranged from around 11/100 000 (200 cases) in North West Thames 


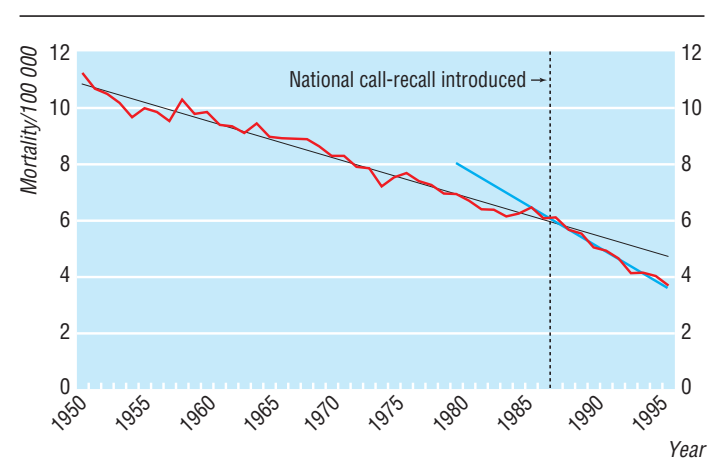

Fig 5 Age standardised mortality from cervical cancer, England, 1950-97

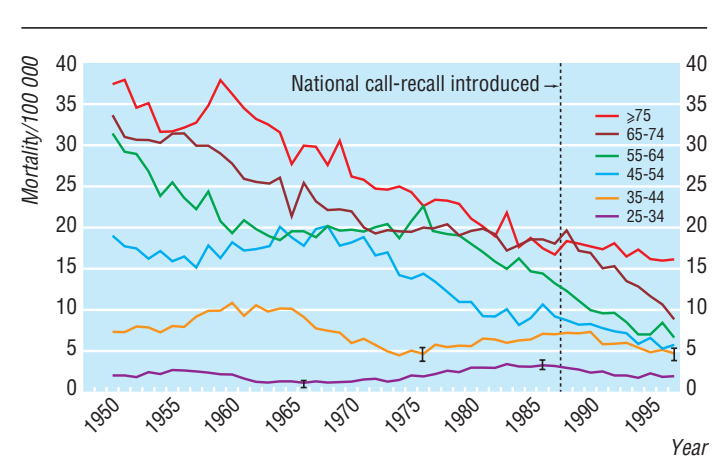

Fig 6 Age specific mortality from cervical cancer, England, 1950-97

to $23 / 100000$ (280 cases) in Mersey. ${ }^{13}$ Incidence fell in all regions between 1990 and 1995 .

\section{Mortality}

From 1950 to 1987 total mortality from cervical cancer fell steadily by just over $1.5 \%$ each year, from $11.2 / 100000$ (2500 deaths) to 6.1/100000 (1800 deaths). The rate of fall then trebled, and by 1997 mortality had fallen to $3.7 / 100000$ (fig 5). The 1150 deaths in 1997 represented $2 \%$ of cancer deaths in women and $0.4 \%$ of all deaths in women.

Age specific mortality has, however, changed differently in the various age groups. In the youngest women (25-34 years) mortality trebled from around 1/100 000 (30 deaths) in the mid-1960s to a plateau of around 3/100 000 (100 deaths) in the mid-1980s (fig 6). Mortality in all the other age groups fell, but at different times.

For the cohort of women aged 25-34 in the mid-1980s-that is, women born in the mid-1950smortality was three times higher than it had been for women aged 25-34 in the mid-1960s. ${ }^{20}{ }^{21}$ Cervical cancer mortality in each birth cohort historically increased with age up to 60 years. ${ }^{21}$ If the raised risk and pattern of mortality are assumed for women born in the mid1950 s, by 1997 mortality would have increased to around 14/100 000 in women aged 35 to 44, and (with a similar projection based on a doubling of mortality for the cohort born in the mid-1940s) to around $19 / 100000$ in women aged 45 to 54 . These rates are far higher than those actually observed (around $5 / 100000$ in both age groups (fig 6)). Applying the difference between the projected and actual mortality in 1997 to the number of women in each age group suggests that screening might have prevented 320 deaths in women aged 35-44 and 430 deaths in women aged 45-54. In addition, mortality in women aged 25-34 in 1997 was one third lower than in the peak in the mid-1980s so a further 50 deaths may have been prevented in this age group.

\section{Discussion}

\section{Screening programme}

Cervical screening by the smear test meets some of the criteria for screening programmes laid down by the World Health Organisation, ${ }^{22}$ but not the two which are probably the most important: cervical cancer in England is relatively uncommon and its natural course is not well understood. Although the effectiveness of screening has never been properly demonstrated in randomised controlled trials, firm evidence comes from the Nordic countries, where the implementation of widely different policies resulted in sharply contrasting trends in incidence and mortality. ${ }^{23}$ Even so, many operational features of the cervical screening process in England have been heavily criticised. ${ }^{1024-26}$

Nevertheless, many smears are technically unsatisfactory, and there are wide variations in the proportions that are unsatisfactory among the regional health authorities. ${ }^{10}$ Interpretation of smears, particularly for the minor changes which give rise to most reported abnormalities,$^{10}$ is unreliable. Laboratories vary widely in their use of result categories, and quality assurance is a continuing problem. ${ }^{24}{ }^{25}$

The smear test has both low sensitivity and low specificity. ${ }^{26}$ Many lesions, particularly mild or moderate dyskaryosis in younger women, will regress, and not all cases of cervical intraepithelial neoplasia grade III will progress to invasive cancer. ${ }^{26}$ Conversely, invasive cancer may arise without any evidence of progression through a series of precancerous stages. ${ }^{26}$ Reviews of the cytological history of women with known invasive cancer indicate that many had a series of normal smear test results before diagnosis. ${ }^{26}$

Colposcopy with biopsy is not risk free. An "abnormal" smear test result, even if followed by a negative result on recall, may cause long term distress and anxiety, difficulties in obtaining life insurance, worries about the effect of treatment on subsequent reproductive ability, and psychosexual trauma. ${ }^{24}$

The annual cost of the screening programme is $£ 132$ million. ${ }^{10}$ This is about four times the cost of the breast screening programme, which aims to reduce annual breast cancer deaths in women aged 55 to 69 by 1250 . Costs of cervical screening could be reduced substantially, with little loss in effectiveness by screening all women every five years-there is little benefit, but enormous increase in costs in opportunistic screening at shorter intervals than those recommended. ${ }^{10}{ }^{23}$ It would also be possible to reduce costs by not screening women under 25 and by not continuing to screen women over 50 who have had two or three consecutive normal results. ${ }^{27}{ }^{28}$ Screening women over 65 , particularly those who have never had a smear, could, however, reduce mortality through diagnosis of cancer at an early stage. ${ }^{29}$

Wilkinson et al have suggested that targeting high risk groups might improve the effectiveness of screening, ${ }^{30}$ but the four high risk categories considered have 
fairly low odds ratios. Women at increased risk would therefore comprise a large proportion of the population, and the resulting stigmatisation would be socially unacceptable.

\section{Effectiveness}

Before the introduction of the national call and recall system and of incentive payments to general practitioners the cervical screening programme in England was largely ineffective, owing mainly to problems of organisation. ${ }^{7023}$ Most cytological tests were performed on women presenting for obstetric, gynaecological, or contraceptive reasons. At least two thirds of women with invasive cervical cancer had never been screened; for women over 40 (among whom $70 \%$ of cases occurred) over $90 \%$ had never been screened. ${ }^{31}$

Cook and Draper noted the large increase in incidence of carcinoma in situ and judged that screening might have prevented a potential increase in both the incidence of invasive disease and mortality. ${ }^{32}$ Parkin et al estimated that, up to 1978, screening had prevented $25 \%$ of potential cases of invasive disease. ${ }^{33}$ On the other hand, Murphy et al related the screening effort in different parts of Great Britain to variations in incidence, mortality, and hysterectomy rates and found no evidence that the burden of cervical cancer would have been higher without the screening programme. ${ }^{34}$

The NHS cervical screening programme has recently achieved a high coverage of the target age group. It has particularly improved coverage of older women and women in lower social classes, who were most at risk and previously largely unscreened. ${ }^{10}{ }^{35}$ National guidelines for clinical practice and service delivery have been established, but there have been problems of implementation in inner cities.

If the introduction of national call and recall has had an effect, there should have been some increases in registrations of in situ disease; a small increase in the incidence of invasive cancer in areas or age groups where coverage was previously poor; a large fall in the incidence of invasive disease across a wide age range and in all parts of the country; possibly a down staging of invasive disease; and lower mortality than would have been expected. Our data show that these changes have occurred.

Registration of in situ disease has increased in parallel with the numbers of smears taken. It is difficult to distinguish increased incidence from improved registration, but changes in completeness are unlikely to produce artefactual trends which affect only particular age groups. ${ }^{32}$ There are, however, known problems of misclassification of cervical cancer, and in the North Western region under-registration of invasive disease was about $9 \%$ overall. ${ }^{36}$

The plateau in the overall incidence of invasive cervical cancer up to 1988 concealed a complex pattern of changes in the age specific rates. The patterns suggest a cohort effect. Other analyses (including with age period cohort models) ${ }^{37}$ have indicated peaks in risk for women born at the end of the 19th century, in the mid-1920s, and after 1950. These women would have been in their late teens and early 20 s, and hence becoming sexually active, at the times of the first world war, the second world war, and the introduction of oral contraceptives, respectively.
- The coverage of the NHS cervical screening programme has increased greatly but several problems remain

- Rates of in situ cervical cancer have continued to rise in women aged 20-29

- Improvements in the screening programme have led to a $35 \%$ fall in incidence of invasive disease

- Reductions in mortality over the past 40 years in women aged over 54 are not related to screening, but in women under 55 screening may have prevented 800 deaths in 1997

Since the introduction of national call and recall in 1988 there has been an overall fall of $35 \%$ in the incidence of invasive cervical cancer, reflecting falls in the age specific rates for all women aged from 30 to 74 years and in all regions of England. Studies based in the regional cancer registries indicate that since 1988 the distribution of stage has shifted towards earlier stages. ${ }^{38}$ And a retrospective case-control study of invasive cancers diagnosed in 1992 has suggested that without screening there would have been 2000 (57\%) more cases ${ }^{39}$ although this may be an overestimate. ${ }^{26}$ We therefore conclude that the fall in incidence is directly related to the increased coverage of screening.

\section{Mortality}

Interpretation of trends in mortality data presents several problems. Firstly, mortality may be affected by changes in survival. But there have been no significant improvements in treatment for cervical cancer over the past 20 years, and there is no evidence that stage specific survival rates have improved substantially. Secondly, recording of cause of death may not always be accurate, and attempts to improve death certification may lead to artefactual changes. Thirdly, the proportion of deaths ascribed to "cancer of the uterus, site unspecified" has varied ${ }^{32}$ and will have decreased as death certification improved.

For mortality, as with the incidence of invasive disease, the long term downward trend which accelerated after 1988 concealed a complex pattern of changes in the age specific rates. These changes reflect the cohort effects in incidence. ${ }^{20}{ }^{21}{ }^{40}$ Little, if any, of the observed long term fall in mortality up to the late 1980 s can be ascribed directly to screening because relatively few women dying from cervical cancer aged over 55 years would have been screened, and it was in these women that the mortality was highest and the falls were largest. ${ }^{31}$ The situation for younger women, however, is different. Raffle ${ }^{40}$ estimated that for women born since 1930, screening prevented about 660 deaths in 1995. The latest data indicate that for women aged 25 to 54 screening might have prevented 800 deaths from cervical cancer in 1997.

Members registries (directors) of the United Kingdom Association of Cancer Registries are: East Anglian (C H Brown, T W Davies), Information and Statistics Division of the NHS in Scotland (D Brewster), Merseyside and Cheshire (E M I Williams), North Western (C B J Woodman), Northern and Yorkshire (D Forman), Northern Ireland (A Gavin), Office for 
National Statistics (M J Quinn), Oxford (M Roche), South and West (J A E Smith), Thames (G Matthews), Trent (J Botha), Wales (J Steward), West Midlands (G M Lawrence).

We thank Michel Coleman, Tim Devis, Karen Dunnell, and John Fox at the Office for National Statistics for advice on drafts of this paper.

(c) Crown copyright.

Contributors: MQ and EA had the original idea for the study and together with $\mathrm{PB}$ and $\mathrm{JJ}$ collated and checked all the data The paper was written jointly by all four authors. All the directors of the cancer registries in England contributed data, and some commented on drafts of the paper. MQ is the guarantor.

Funding: None.

Competing interests: None declared.

1 Reeves GK, Appleby P, Beral V, Quinn MJ, Babb PJ, Jones J. Cancer survival in England and Wales: 1981 and 1989 registrations. London: Office for National Statistics, Imperial Cancer Research Fund, 1998. (Monitor MB1 98/1.)

2 Berrino F, Sant M, Verdecchia A, Capocaccia R, Hakulinen T, Estève J, eds. Survival of cancer patients in Europe. The EUROCARE study. Lyons: International Agency for Research on Cancer, 1995. (IARC scientific publication No 132.)

3 Schrijvers CTM, Mackenbach JP, Lutz J-M, Quinn MJ, Coleman MP. Deprivation, stage at diagnosis and cancer survival. Int J Cancer 1995;63:324-9.

4 Beral V. Cancer of the cervix: a sexually transmitted infection? Lancet $1974 ; \mathrm{i} ; 1037-40$.

5 Woodman CBJ, Rollason T, Ellis J, Tierney R, Wilson S, Young L. Human papillomavirus infection and risk of progression of epithelial abnormalities of the cervix. Br J Cancer 1996;73:553-6.

6 Brinton LA. Epidemiology of cervical cancer-overview. In: Muñoz N, Bosch FX, Shah KV, Meheus A, eds. The epidemiology of human papillomavirus and cervical cancer. Lyons: International Agency for Research on Cancer, 1992:3-23. (IARC scientific publication No 119.)

7 Farmery E, Gray JAM. Report of the first five years of the NHS cervical screening programme. Oxford: National Coordinating Network, 1994

8 Royal College of Obstetricians and Gynaecologists. Report of the intercollegiate working party on cervical cytology screening. London: RCOG, 1987.

9 Department of Health and Social Security. Health services management:cervical cancer screening. Heywood: DHSS, 1988. (Health circular HC(88)1.)

10 National Audit Office. The performance of the NHS cervical screening programme in England. Report by the comptroller and auditor general. London: Stationery Office 1998

11 Department of Health. General practice in the NHS: a new contract. London: DoH, 1989.

12 Department of Health. Cervical screening programme, England: 1994-95 to 1996-97. London: DoH, 1996-97. (Statistical bulletins 1996/3, 1996/26 1997/27.)

13 Office of Population Censuses and Surveys. Cancer statistics-registrations, England and Wales, 1971 to 1992. London: HMSO, 1979-98. (Series MB1 Nos $1,2,4,5,7,8,10-16,18-25$.)

14 Huggett C. Review of the quality and comparability of data held by regional cancer registries. Bristol: Bristol Cancer Epidemiology Unit, 1995.

15 Quinn MJ, Allen E, on behalf of the United Kingdom Association of Cancer Registries. Changes in incidence of and mortality from breast cancer in England and Wales since introduction of screening. BMJ 1995;311:1391-5.

16 Estève J, Benhamou E, Raymond L. Descriptive epidemiology. Statistical methods in cancer research. Vol IV. Lyons: International Agency for Research on Cancer, 1994. (IARC scientific publication No 128.)
17 Roberts A. Cervical cytology in England and Wales, 1965-80. Health Trends 1982;14:41-2.

18 Department of Health and Social Security. Cervical cytology 1980 to 1987 88. Summary information from form SBH140, England. London: DHSS, 1981-88.

19 Department of Health. Cervical cytology, 1988-89 to 1993-94. Summary information from Form KC53, England. London: DoH, 1989-94

20 Osmond C, Gardner MJ, Acheson ED. Analysis of trends in cancer mortality in England and Wales during 1951-80 separating changes associated with period of birth and period of death. BMJ 1982;284:1005-8

21 Sasieni P, Cuzick J, Farmery E. Accelerated decline in cervical cancer mortality in England and Wales. Lancet 1995;346:1566-7.

22 Wilson JMG, Jungner, G. Principles and practice of screening for disease Geneva: World Health Organisation, 1968. (WHO public health paper 34.)

23 Day NE. Screening for cancer of the cervix. J Epidemiol Comm Health 1989;43:103-6.

24 Raffle AE, Alden B, Mackenzie EFD. Detection rates for abnormal cervical smears: what are we screening for? Lancet 1995;345:1469-73.

25 Johnson J. Media focus on failures of screening programme. $B M$ J 1997;314:1630.

26 Moss S. Screening for cancer of the cervix. In: Chamberlain J, Moss S, eds Evaluation of cancer screening. London: Springer, 1996:15-32.

27 Miller AB, Chamberlain J, Day NE, Hakama M, Prorok PC. Report on a workshop of the UICC project on evaluation of screening for cancer. Int J Cancer 1990;46:761-9.

28 Van Wijngaarden WJ, Duncan ID. Rationale for stopping cervical screening in women over 50. BMJ 1993;306:967-71.

29 Fletcher A. Screening for cancer of the cervix in elderly women. Lance 1990;335:97-9.

30 Wilkinson C, Peters TJ, Harvey IM, Stott NCH. Risk targeting in cervical screening: a new look at an old problem. Br J Gen Practice 1992;42:435-8.

31 Chamberlain J. Screening for early detection of cancer. In: Tiffany R, Pritchard AP, eds. Oncology for nurses and health care professionals. Vol 1. London: Harper and Row, 1988:155-73.

32 Cook GA, Draper GJ. Trends in cervical cancer and carcinoma in situ in Great Britain. Br J Cancer 1984;50:367-75.

33 Parkin DM, Nguyen-Dinh X, Day NE. The impact of screening on the incidence of cervical cancer in England and Wales. Br J Obstet Gynaecol 1985;92:150-7.

34 Murphy MFG, Campbell MJ, Goldblatt PO. Twenty years' screening for cancer of the uterine cervix in Great Britain 1964-84: further evidence for its ineffectiveness. J Epidemiol Comm Health 1987;42:49-53.

35 Austoker J. Screening for cervical cancer. BMJ 1994;309:241-7.

36 Lancaster G, Moran T, Woodman C. Towards achieving the health of the nation target for cervical cancer: accuracy of cancer registration. J Pub Health Med 1992;16:50-2.

37 Coleman MP, Estève J, Damiecki P, Arslan A, Renard H. Trends in cancer incidence and mortality. Lyons: International Agency for Research on Cancer, 1993. (IARC scientific publications No 121.)

38 Herbert A, Breen C, Bryant TN, Hitchcock A, Macdonald H, Millward-Sadler GH, et al. Invasive cervical cancer in Southampton and south west Hampshire: effect of introducing a comprehensive screening programme. J Med Screening 1996;3:23-8.

39 Sasieni PD, Cuzick J, Lynch-Farmery E and the National Coordinating Network for Cervical Screening Working Group. Estimating the efficacy of screening by auditing smear histories of women with and without cervical cancer. Br J Cancer 1996;73:1001-5.

40 Raffle AE. Deaths from cervical cancer began falling before screening programmes were established. $B M J$ 1997;315:953-4.

(19January 1999)

Cite this article as:

Quinn M, Babb P, Jones J, Allen E on behalf of the

United Kingdom Association of Cancer Registries.

Effect of screening on incidence of the mortality

from cancer of the cervix in England: evaluation

based on routinely collected statistics [abridged

version]. $B M J$ 1999;318:904-8. (full version:

www.bmj.com/cgi/content/full/318/7188/904) 